Case Report

\title{
Colorectal Microcarcinoids in Association with Long-Term Exposure to Urinary Content: A Case Report and Review of the Literature
}

\author{
Grace W. Weyant, Dipti M. Karamchandani, and Negar Rassaei \\ Department of Pathology, Penn State Milton S. Hershey Medical Center, 500 University Drive, P.O. Box 850, MC H179, \\ Hershey, PA 17033, USA \\ Correspondence should be addressed to Grace W. Weyant; gweyant@hmc.psu.edu
}

Received 8 January 2015; Accepted 16 March 2015

Academic Editor: Dengfeng Cao

Copyright @ 2015 Grace W. Weyant et al. This is an open access article distributed under the Creative Commons Attribution License, which permits unrestricted use, distribution, and reproduction in any medium, provided the original work is properly cited.

Long-term exposure of colonic mucosa to urinary content and its association with increased risk of infection, mechanical and biochemical irritation, and malignancy have been described in the literature. Existing case reports and studies depict the low but distinct risk of malignancy in gastrointestinal segments which come in contact with urinary content as a result of surgical correction of urinary tract abnormalities. However, these reports are largely limited to colonic adenocarcinoma and urothelial cell carcinoma. Late urointestinal carcinoma in patients with ileal incorporation into the urinary tract has also been reported. To the best of our knowledge, however, there is only one case report documenting neuroendocrine (NE) cell hyperplasia in colonic mucosa after long-term cystoplasty. Our case is the first to describe microcarcinoids and diffuse NE hyperplasia occurring in a patient with congenital anorectal anomalies, resulting in long-term exposure of colonic mucosa to fecal stream and urinary content. This case, in conjunction with the reported cases in the literature, raises the distinct possibility of an association between exposure of colonic mucosa to urine and long-term development of malignancy, including NE neoplasms.

\section{Introduction}

Gastrointestinal segments are commonly utilized for urinary tract reconstruction when the creation of a conduit or bladder replacement is indicated $[1,2]$. Long-term exposure of colonic mucosa to urinary content is associated with risk of infection, mechanical and biochemical irritation, and malignancy [1, 3]. Rare case reports and studies of malignancy, particularly colonic adenocarcinoma and urothelial cell carcinoma, have been reported in the literature in this setting [1, 4, 5]. Rarely, neuroendocrine (NE) cells, which are usually inconspicuous occupants within the colonic mucosa, may become hyperplastic $[2,6]$. We herein describe the first case of microcarcinoids with diffuse NE cell hyperplasia occurring in a patient with a history of congenital imperforate anus and colovesicular fistula, which resulted in prolonged exposure of colonic mucosa to urinary content.

\section{Case Presentation}

A 29-year-old male presented to our tertiary facility with imperforate anus and associated urinary incontinence. The patient had a history of multiple congenital abnormalities detected at birth, including atrial septal defect (ASD), persistent left-sided superior vena cava, cardiac conduction abnormalities, Wolff-Parkinson-White (WPW) syndrome, and vertebral anomalies. The gastrointestinal and genitourinary abnormalities were comprised of malformations including imperforate anus with the rectum terminating to the left and above the sphincteric complex, a connection between the rectum and bladder, and left vesicoureteral reflux.

He underwent open cardiac surgery for repair of the ASD and ablation of the WPW foci. Also, shortly after birth, the patient underwent surgery during which a loop transverse colostomy was created and an anoplasty was 


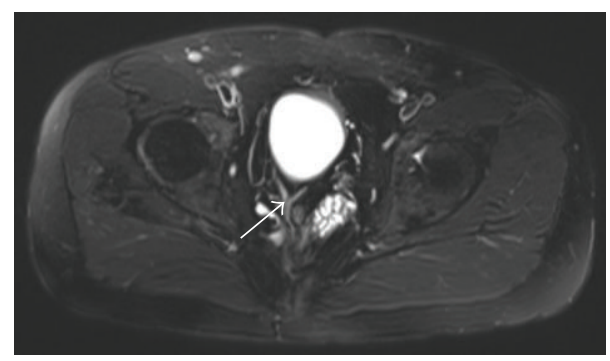

FIGURE 1: MRI of pelvis at the level of the bladder and rectum. Arrow: colovesicular fistula.

attempted unsuccessfully. Subsequently at the age of 26, a posterior sagittal anorectoplasty could not be completed due to technical difficulties. For the past several years, the patient had stool from the proximal portion of his colostomy and urine from the distal nonfunctional limb with persistent exposure of both colostomy limbs to urine and fecal material.

On physical examination, a left upper quadrant colostomy and imperforate anus were confirmed. MRI demonstrated the abnormalities stated above and suggested a mass near the colovesicular fistula (Figure 1). Endoscopic evaluation with colonoscopy and cystoscopy with biopsies did not demonstrate any pathologic alterations. Examination under anesthesia with muscle stimulation demonstrated functional anal sphincter muscles. Thus, the patient underwent takedown of the colovesicular fistula, closure of the bladder neck, reimplantation of the right ureter, small bowel resection with creation of an ileovesicostomy, colostomy takedown, colocolonic anastomosis, low anterior resection, posterior sagittal anorectoplasty, and coloanal anastomosis with a diverting loop ileostomy. He recovered well from the surgery without complications.

The specimen consisted of a segment of rectum containing the colovesicular fistula and a segment of sigmoid colon submitted separately, measuring $8.2 \mathrm{~cm}$ and $6.8 \mathrm{~cm}$ in length, respectively. Examination of initial representative sections revealed the incidental finding of neuroendocrine cell hyperplasia, after which the entire rectal specimen was submitted for microscopic evaluation. Histologic sections of the rectum and sigmoid demonstrated multiple microscopic foci of neuroendocrine cell hyperplasia with rare foci of microcarcinoids, the largest of which measured $5 \mathrm{~mm}$ in greatest dimension. These foci involved the mucosa and submucosa and were composed of small clusters of mediumsized cells with small round to oval nuclei containing fine chromatin with a salt and pepper appearance (Figures 2 and 3 ). The mitotic rate was 1 per 10 high power fields. Necrosis was absent. By immunohistochemistry, the lesional cells were strongly and diffusely immunoreactive with synaptophysin and chromogranin (Figure 4). The proliferative index, assessed with Ki-67, was less than 2\% (Figure 5). Additionally, serum chromogranin A levels were found to be normal.

\section{Discussion}

Review of the literature demonstrates a risk of malignancy in gastrointestinal segments exposed to urine following

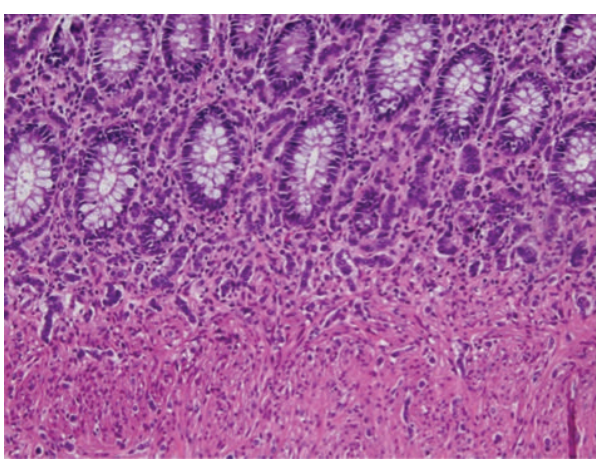

FIGURE 2: Clusters and cords of medium-sized cells with small round to oval nuclei dispersed within the colonic mucosa $(\mathrm{H} \& \mathrm{E}, \times 200)$.

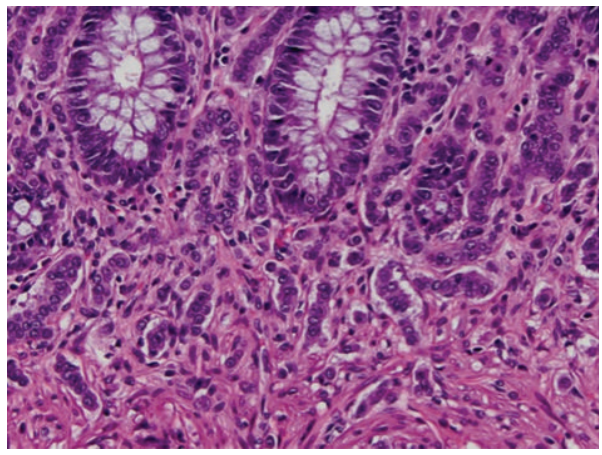

FIgURE 3: At high power, the cells contain fine chromatin. Nucleoli and mitoses are inconspicuous (H\&E, $\times 400)$.

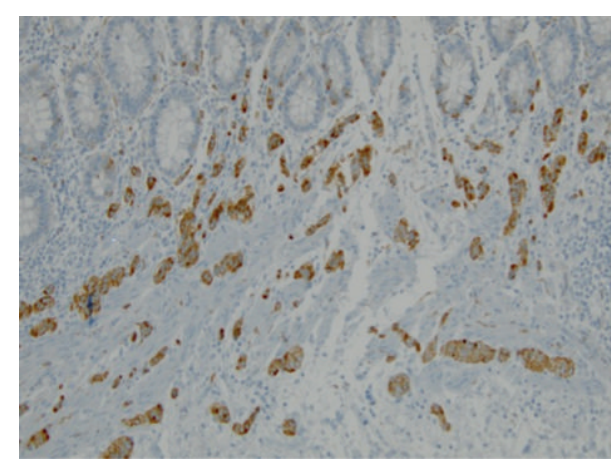

FIGURE 4: Strong and diffuse immunoreactivity with synaptophysin confirms neuroendocrine differentiation (Synaptophysin, $\times 200$ ).

surgical correction of urinary tract abnormalities [3-5, 7]. Late occurrence of colonic adenocarcinoma after ureterosigmoidostomy has been reported with an incidence of 5 to $40 \%$, representing a significant increase compared to the agematched general population $[1,8,9]$. Also, a higher risk of malignancy in bowel segments after cystoplasty or urinary conduit reconstruction has been documented $[3,10,11]$. The most commonly reported cancers include adenocarcinoma and urothelial cell carcinoma; however, rare cases of squamous cell carcinoma have been reported as well [1]. Typically, these tumors develop within a few years to decades after the surgical procedure and are located at the anastomotic site [12]. 


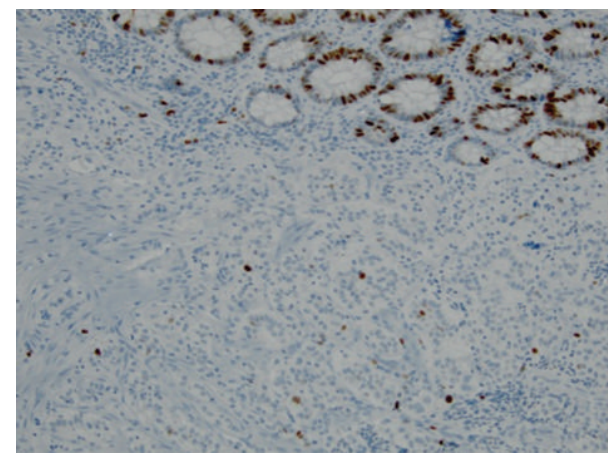

Figure 5: The proliferation index was $<2 \%(\mathrm{Ki}-67, \times 200)$.

While the physiopathologic mechanism is not well known, it has been postulated that contact among urine, feces, urothelium, and colonic epithelium at the anastomotic site of ureterosigmoidostomies activates fecal carcinogens $[8,13]$. Also, bacteriuria and production of $\mathrm{N}$-nitrosamine have been considered responsible factors for tumorigenesis $[11,12]$.

Neuroendocrine cell hyperplasia (NEH) is a wellestablished entity in the lung and in the upper gastrointestinal tract, particularly stomach [6] and pancreas. However, there is no such well-defined entity in the colon. NE tumors in the colon represent approximately 1-2\% of colorectal neoplasms. In the rectum, this type of tumor typically occurs in the 6th decade of life and has a low propensity for lymph node involvement and distant metastasis [14-16].

While the association of NEH with certain entities such as inflammatory bowel disease and diversion colitis is well documented $[2,17,18]$, to the best of our knowledge, there is only one case report describing NEH in colonic tissue used for cystoplasty [2]. Kochevar reports a case of adenocarcinoid tumor arising in an ureteroileal conduit [7]. These studies describe the development of different types of cellular hyperplasia and malignancy in intestinal mucosa in contact with urine after ureterosigmoidostomy or cystoplasty exposing intestinal mucosa to urine with no or low fecal stream. Our case is the first to show microcarcinoids and NEH in colonic mucosa exposed to urinary content due to the type of conduit implemented. Interestingly, in our case NEH was observed not only at the fistula site but also distantly in the sigmoid, suggesting a more diffuse phenomenon. There was no significant inflammation despite long-term exposure of colonic mucosa to urinary content. The biologic mechanism of this finding is not known; however, the possibility of a process akin to that described in patients with ureterosigmoidostomy and cystoplasty who develop carcinoma has been raised.

\section{Conclusion}

Review of the literature demonstrates that few cases have been reported exhibiting the occurrence of different types of malignancy in association with long-term exposure of colonic mucosa with urinary content. Our case shows development of $\mathrm{NEH}$ and microcarcinoids in association with long-term exposure of colonic mucosa to urinary content. While uncommon, the reported cases establish the possibility of development of malignancy including NE neoplasms in the urointestinal tract postoperatively. Thus, one may recommend long-term follow-up of those patients who have undergone a surgical procedure exposing intestinal mucosa to urinary contents with or without fecal stream.

\section{Conflict of Interests}

The authors declare that there is no conflict of interests regarding the publication of this paper.

\section{References}

[1] A. A. Shokeir, M. Shamaa, M. M. El-Mekresh, M. El-Baz, and M. A. Ghoneim, "Late malignancy in bowel segments exposed to urine without fecal stream," Urology, vol. 46, no. 5, pp. 657661, 1995.

[2] K. Oien, M. Akyol, and G. Lindop, "Neuroendocrine cell hyperplasia in colonic tissue used for long term augmentation cystoplasty," Journal of Clinical Pathology, vol. 51, no. 3, pp. 258261, 1998.

[3] R. B. Filmer and J. R. Spencer, "Malignancies in bladder augmentations and intestinal conduits," Journal of Urology, vol. 143, no. 4, pp. 671-678, 1990.

[4] J. Moorcraft, C. E. H. DuBoulay, P. Isaacson, and J. D. Atwell, "Changes in the mucosa of colon conduits with particular reference to the risk of malignant change," British Journal of Urology, vol. 55, no. 2, pp. 185-188, 1983.

[5] J. S. Little Jr., L. W. Klee, D. M. Hoover, and R. C. Rink, "Longterm histopathological changes observed in rats subjected to augmentation cystoplasty," The Journal of Urology, vol. 152, no. 2, part 2, pp. 720-724, 1994.

[6] Y. Dayal, R. A. DeLellis, and H. J. Wolfe, "Hyperplastic lesions of the gastrointestinal endocrine cells," The American Journal of Surgical Pathology, vol. 11, supplement 1, pp. 87-101, 1987.

[7] J. Kochevar, "Adenocarcinoid tumor, goblet cell type, arising in a ureterioleal conduit: a case report," Journal of Urology, vol. 131, no. 5, pp. 957-959, 1984.

[8] R. F. Gittes, "Carcinogenesis in ureterosigmoidostomy," Urologic Clinics of North America, vol. 13, no. 2, pp. 201-205, 1986.

[9] G. W. Leadbetter Jr., P. Zickerman, and E. Pierce, "Ureterosigmoidostomy and carcinoma of the colon," The Journal of Urology, vol. 121, no. 6, pp. 732-735, 1979.

[10] D. A. Husmann and H. M. Spence, "Current status of tumor of the bowel following ureterosigmoidostomy: a review," The Journal of Urology, vol. 144, no. 3, pp. 607-610, 1990.

[11] M. S. Chiang, J. P. Minton, K. Clausen, H. W. Clatworthy, and H. A. Wise II, "Carcinoma in a colon conduit urinary diversion," The Journal of Urology, vol. 127, no. 6, pp. 1185-1187, 1982.

[12] W. Mansson and R. Willen, "Mucosal morphology and histochemistry of the continent cecal reservoir for urine," Journal of Urology, vol. 139, no. 6, pp. 1199-1201, 1988.

[13] N. Daher, R. Gautier, H. Abourachid, C. Decaens, and J. Bara, "Rat colonic carcinogenesis after ureterosigmoidostomy: pathogenesis and immunohistological study," The Journal of Urology, vol. 139, no. 6, pp. 1331-1336, 1988.

[14] E. Solcia, R. Fiocca, L. Villani, O. Luinetti, and C. Capella, "Hyperplastic, dysplastic, and neoplastic enterochromaffinlike-cell proliferations of the gastric mucosa. Classification and 
histogenesis," The American Journal of Surgical Pathology, vol. 19, supplement 1, pp. S1-S7, 1995.

[15] G. Klöppel, M. Anlauf, and A. Perren, "Endocrine precursor lesions of gastroenteropancreatic neuroendocrine tumors," Endocrine Pathology, vol. 18, no. 3, pp. 150-155, 2007.

[16] G. Rindi and E. Solcia, "Endocrine hyperplasia and dysplasia in the pathogenesis of gastrointestinal and pancreatic endocrine tumors," Gastroenterology Clinics of North America, vol. 36, no. 4, pp. 851-865, 2007.

[17] G. B. M. Lindop, "Enterochromaffin cell hyperplasia and megacolon: report of a case," Gut, vol. 24, no. 6, pp. 575-578, 1983.

[18] A. P. Griffiths and M. F. Dixon, "Microcarcinoids and diversion colitis in a colon defunctioned for 18 years-report of a case," Diseases of the Colon \& Rectum, vol. 35, no. 7, pp. 685-688, 1992. 


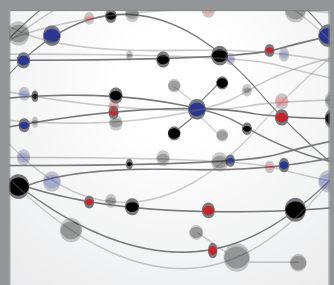

The Scientific World Journal
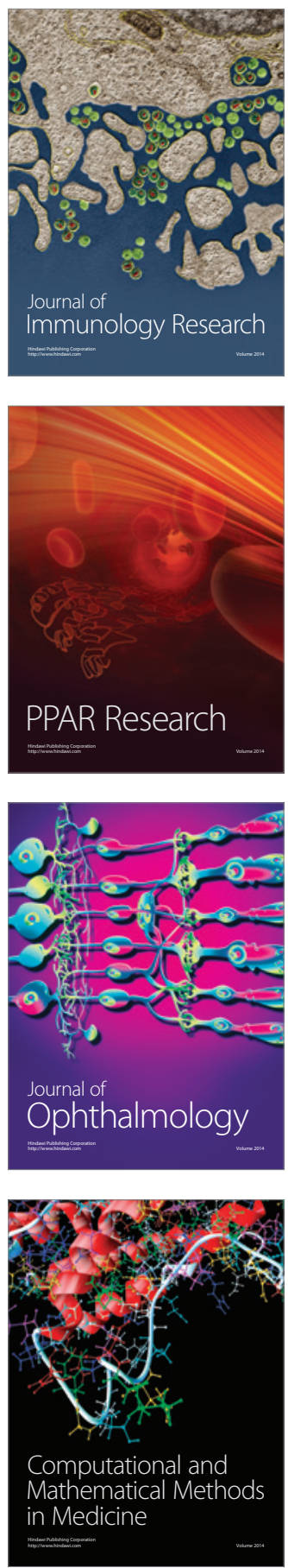

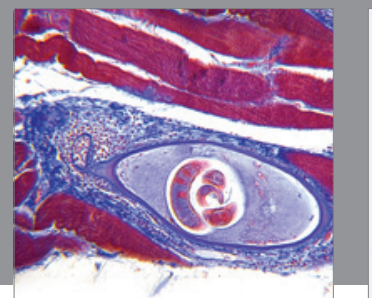

Gastroenterology

Research and Practice
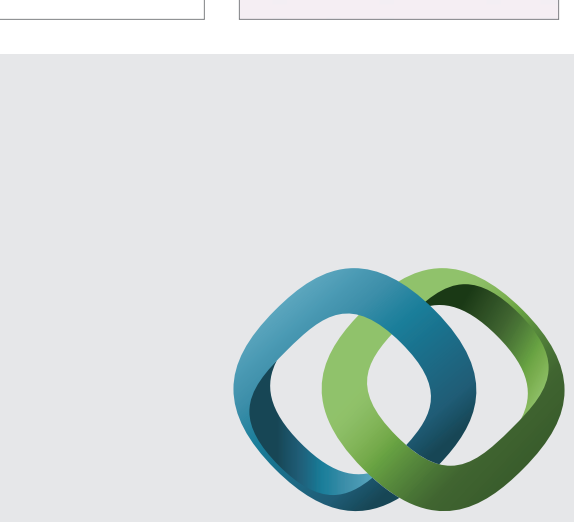

\section{Hindawi}

Submit your manuscripts at

http://www.hindawi.com
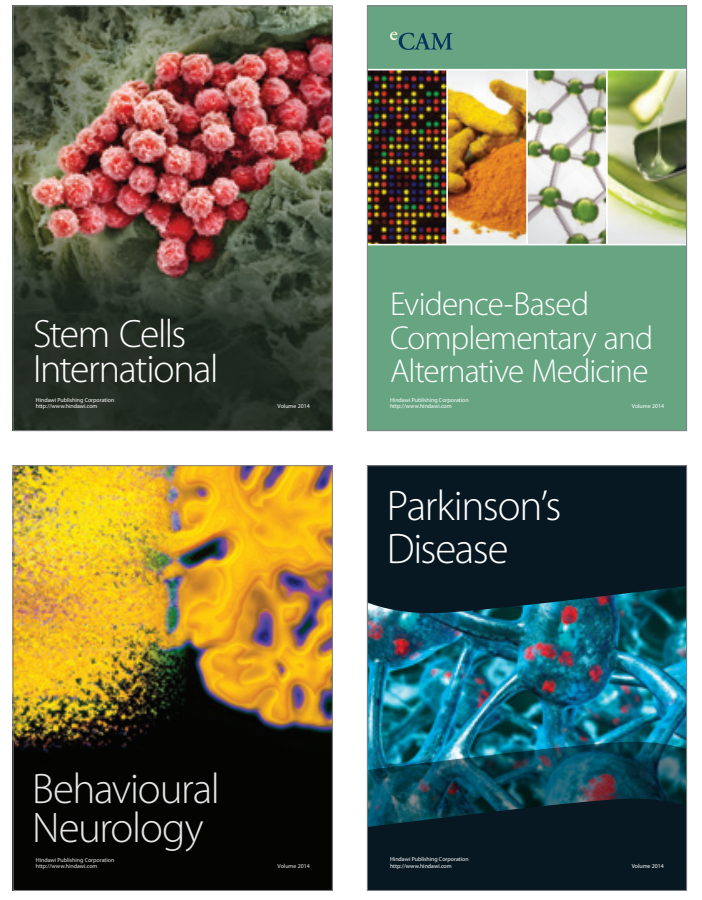
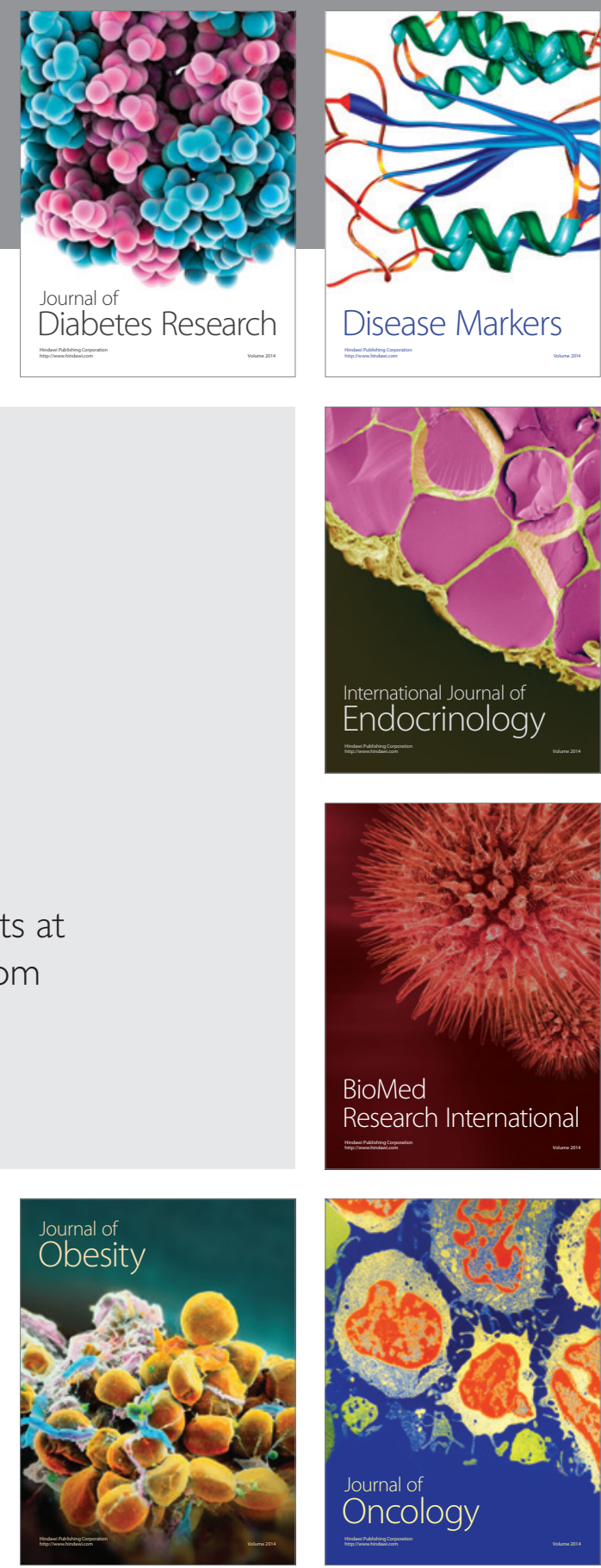

Disease Markers
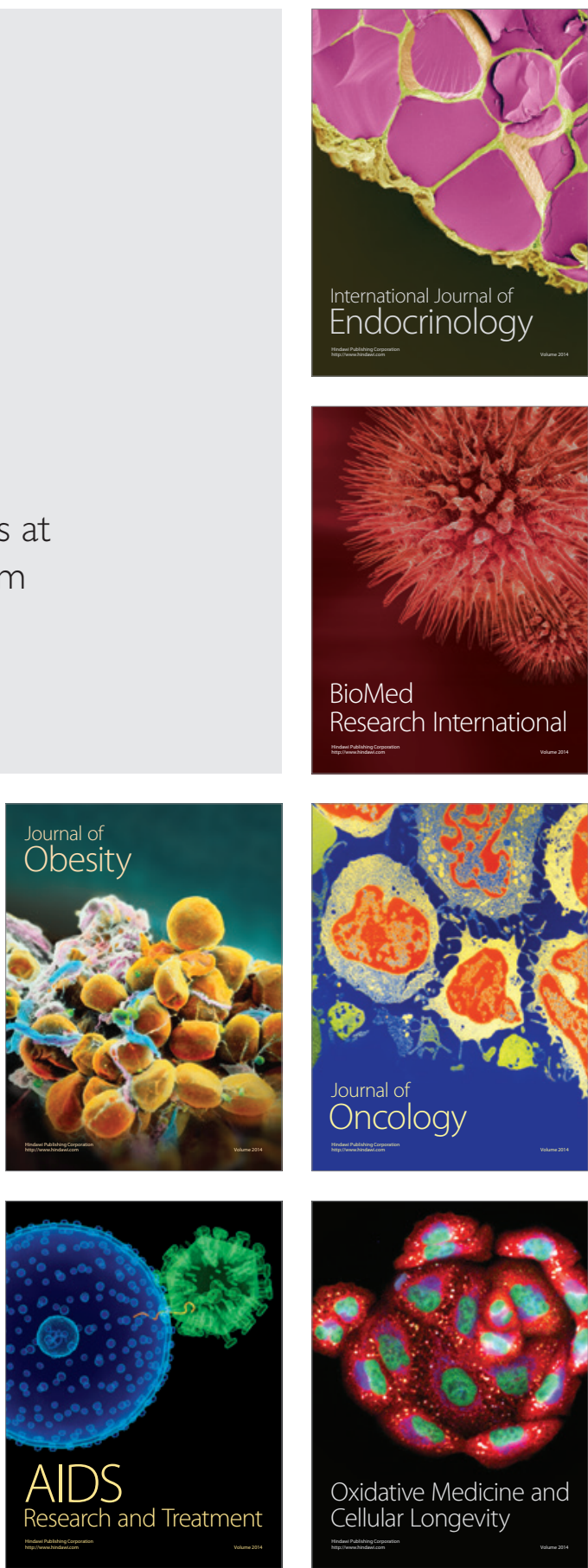